\title{
A Lei de Acesso à Informação como instrumento de controle social: diagnóstico dos municípios do sul do Brasil à luz do artigo $8^{\circ}$ da lei 12527/2011
}

\begin{abstract}
RESUMO
Este estudo objetiva identificar qual o percentual de municipios da região sul do Brasil divulgam as informações exigidas no art. $8^{\circ}$ da Lei de Acesso à Informação em seus sítios eletrônicos. Em relação ao objetivo, esta pesquisa pode ser classificada como descritiva, de lógica dedutiva, abordagem qualitativa, enquadrada como bibliográfica e documental e realizada por meio de consultas aos sítios eletrônicos de 216 municípios. A partir dos dados coletados, conclui-se que, de modo geral, os municípios da região sul do Brasil, com população superior a 10 mil habitantes, atendem parcialmente aos requisitos apresentados no Art. 8 da LAl. Com esses resultados, espera-se que os cidadãos possam cobrar dos governantes a melhoria na qualidade das informações de interesse público divulgadas, exercendo assim o controle social e contribuindo para a melhoria da gestão pública e a inibição da corrupção.
\end{abstract}

Palavras-chave: Lei de acesso à informação. Transparência. Controle Social.

Marcelo Medeiros da Rosa mmr2801@yahoo.com.br Mestrando em Contabilidade pela Universidade Federal de Santa Catarina (UFSC) - Brasil

Fabiano Domingos Bernardo fabiano_bernardo@hotmail.com Mestre em Contabilidade pela Universidade Federal de Santa Catarina (UFSC) Faculdades Energia (FEAN) - Brasil

Ernesto Fernando Rodrigues Vicente e.fernando@cse.ufs.br Doutor em Administração pela Universidade de São Paulo (USP) Universidade Federal de Santa Catarina (UFSC) - Brasil 


\section{INTRODUÇÃO}

Conhecido internacionalmente como um dos países com a maior carga tributária do mundo, em que o trabalhador atua mais de quatro meses por ano exclusivamente para atender às exigências tributárias (IBPT, 2010), o Brasil apresenta um índice de desenvolvimento humano (IDH) inferior à média da América Latina, ocupando a $79^{\circ}$ posição de 187 países.

Ademais, frequentemente os veículos de comunicação noticiam sobre o mau uso de recursos, peculato e desvios de conduta por parte de gestores e servidores públicos. Por estas razões, o Brasil foi foco de pesquisa da Transparency Internacional, organização sem fins lucrativos cuja missão é promover o fim da corrupção. Em 2012, a entidade divulgou uma pesquisa que apontou que 70\% dos entrevistados considera a corrupção um sério problema no setor público brasileiro.

Corroborando com esse índice, Rocha (2011) afirma que o país está entre as sociedades mais desiguais do mundo, onde, de um lado, apresenta grandes projetos de desenvolvimento e, de outro, apresenta pobreza, analfabetismo e falta de saneamento básico e moradia digna. Ainda, de acordo com o autor, existem recursos suficientes, mas falta justiça e boa gestão.

Neste sentido, Rocha (2011, p. 5) afirma que "nessa conjuntura, corrupção, malversação e desvios de recursos públicos são os maiores responsáveis pelas tragédias vividas pelo povo e, por consequência, os gestores ímprobos são os tiranos de nossa nação".

Uma forma de inibição da corrupção, apontada por Alves (2011), é a garantia do acesso facilitado às informações públicas como forma de aumentar a pressão exercida pelo cidadão e, consequentemente, o aumento da transparência e da accountability na gestão pública. Cabe destacar que o entendimento, para fins desta pesquisa, do termo accountability é o apresentado por Schedler (1999), em que o termo representa a obrigação da Administração abrir-se ao público, explicar e justificar suas ações e subordinação à possibilidade de sanções.

Neste sentido, Soares (2013) afirma que o debate sobre o tema transparência é de grande importância para o exercício da cidadania. Maior transparência permite o controle social mais eficaz sobre os atos dos agentes públicos e, consequentemente, na melhoria dos gastos públicos com a aquisição de bens ou serviços.

De acordo com Jardim (2012), a partir da segunda metade do século XX, o direito à informação tem sido considerado um dos indicadores da cidadania e se consolida de formas distintas e em diversas experiências históricas. Em todas elas, os regimes jurídicos e administrativos que norteiam as relações entre Estado e Sociedade definem, em graus variados, como os agentes, as políticas, as estruturas e as ações institucionais devem interagir com os administrados.

Ainda de acordo com o autor, a aplicação de leis de acesso à informação governamental gera o surgimento de zonas de tensão, espaços de consenso e práticas informacionais, fatores inerentes às dinâmicas requeridas pelo direito à informação. Nesse mesmo processo, salienta Jardim (2012), as demandas por transparência e controle social das sanções do Estado ganham relevo na agenda política e nos modelos de gestão governamentais.

Nesse contexto, entende-se que o controle e a fiscalização dos recursos públicos são instrumentos indispensáveis para a construção de uma sociedade mais justa e equânime e esse controle envolve a participação do cidadão no planejamento e execução dos atos e políticas públicas.

Segundo Rocha (2011), o controle das políticas públicas deve ser exercido por cada cidadão deste país, direito assegurado pela Carta Magna. Isto se justifica, ainda de acordo com o autor porque "os cidadãos são aqueles que estão mais próximos de onde os fatos acontecem e, portanto, podem manter uma fiscalização mais permanente de tudo que é público, de tudo que permanece à coletividade" (ROCHA, 2011, p. 5).

No Brasil, a Constituição Federal de 1988, em seu Art. 5, inciso XXXIII, garantiu à sociedade brasileira o direito à informação, considerado um dos pilares da democracia (BRASIL, 1988). Esse dispositivo não corresponde apenas a um direito civil, mas também um direito político e social que, de acordo com Jardim (2012 p. 2), "acentua a importância jurídica assumida pela informação nas sociedades democráticas".

Embora assegurado aos cidadãos por meio da Constituição Federal, esse direito ainda não possuía regulamentação que pudesse garantir sua aplicabilidade. A ausência de meios afastava os cidadãos de uma das principais ferramentas do controle social: o acesso à informação.

Como forma de preencher a lacuna supracitada, em 18 de novembro de 2011 promulgou-se a Lei $n^{\circ} 12.527$, denominada Lei de acesso à informação - LAl, que regula o acesso à informação previstos, além do artigo $5^{\circ}$ supracitado, no artigo $37 \S 3^{\circ}$ inciso Il e no artigo $216 \S 2^{\circ}$ da Carta Magna (BRASIL, 2011).

Em seu artigo $8^{\circ}$, a LAl dispõe que os entes da Administração Pública devem disponibilizar, de forma próativa, as seguintes informações básicas em sítios oficiais na internet: (i) Registro das competências e da estrutura organizacional, endereços e telefones de suas unidades e horários de atendimento ao público; (ii) Registro de quaisquer repasses ou transferências de recursos financeiros; (iii) Registros de despesas; (iv) Informações referentes a procedimentos licitatórios, inclusive os respectivos editais, e todos os contratos celebrados; (v) Dados gerais para o acompanhamento de programas, ações, projetos e obras; (vi) Respostas às perguntas mais 
frequentes (BRASIL, 2011).

Apesar da exigência de publicação dos dados acima estarem explicitadas na Lei 12.527/2011, nem todos os entes, em especial os municípios, disponibilizam ao público, de forma uniforme, suas informações. Basta consultar, de forma aleatória, os portais de alguns municípios obrigados a divulgar essas informações (acima de 10 mil habitantes) para que seja possível perceber a existência de documentos incompletos ou pouco relevantes para o exercício do controle social.

Assim surgiu a pergunta de pesquisa: As informações previstas no artigo $8^{\circ}$ na Lei de Acesso à Informação estão sendo divulgadas pelos municípios da Região Sul do Brasil em seus sítios eletrônicos?

Para responder à pergunta de pesquisa, objetiva-se identificar qual o percentual de municípios da região sul do Brasil que divulgam as informações exigidas no art. $8^{\circ}$ da Lei de Acesso à Informação nos sítios eletrônicos

Dos 1191 municípios dos estados de Paraná, Rio Grande do Sul e Santa Catarina, apenas 493 estão sujeitos à divulgação das informações uma vez que o parágrafo $4^{\circ}$ do art. $8^{\circ}$ da LAl dispensa os Municípios com menos de 10 mil habitantes de divulgarem na internet as informações mínimas exigidas por esta lei e são esses que fazem parte do universo da presente pesquisa.

A coleta de dados foi realizada no período entre 20 de julho e 02 de agosto de 2015 e abrangeu 216 municípios - número definido por meio de cálculos estatísticos, sendo 72 de cada um dos estados da região estudada. A seleção foi direcionada de forma a permitir a estratificação e análise dos dados: foram analisados os 36 municípios com maior e menor número de habitantes, segundo dados do IBGE (2014).

Quanto à justificativa, entende-se que o tema exerce importante papel no controle social e no combate a corrupção. Procura-se incentivar a participação popular na gestão dos recursos públicos, bem como promover o mecanismo de ampla acessibilidade e transparência regulamentado pela LAI.

Quanto à estrutura, este artigo está dividido em seções que versam sobre os procedimentos metodológicos e estatísticos de definição da amostra adotados na seção metodologia; o direito de acesso às informações públicas; accountability, transparência pública e controle social na sua fundamentação teórica; a apresentação e análise dos resultados na seção resultados; e as conclusões e recomendações para futuros pesquisadores, na última seção.

\section{METODOLOGIA}

A metodologia desta pesquisa se desdobra em enquadramento metodológico e procedimentos para a coleta e tratamento de dados.

\subsection{Enquadramento metodológico}

Em relação ao objetivo, a pesquisa é classificada como descritiva, pois se propôs a descrever características de determinada população (GIL, 1999).

Quanto à lógica de pesquisa, este estudo é dedutivo, pois parte do princípio de que as informações mínimas exigidas pelo artigo $8^{\circ}$ da Lei $12.527 / 2011$ são divulgas pelos municípios da região sul do país.

Em relação ao processo de pesquisa, na coleta de dados utilizaram-se dados secundários, uma vez que as informações foram coletadas em sítios eletrônicos e não diretamente em sistemas gerenciais. Quanto à abordagem utilizada, este estudo é qualitativo, uma vez que os pesquisadores foram os responsáveis pela investigação das informações publicadas em consonância com a LAI e por meio de análises mais profundas (RAUPP; BEUREN, 2003).

Quanto ao resultado da pesquisa, entende-se que, a partir do objetivo estabelecido, trata-se de uma pesquisa aplicada. Esta classificação se dá pelo fato de se buscar a geração de conhecimentos para a solução de um problema específico - no caso, a adequação à Lei de Acesso à Informação.

Sobre os procedimentos técnicos utilizados, a pesquisa é classificada como bibliográfica e documental, pois foi desenvolvida a partir de materiais publicados como livros, artigos, dissertações, teses e internet (GIL, 1999).

Para melhor compreensão do enquadramento metodológico desta pesquisa, desenvolveu-se a Figura 1. 
Figura 1 - Enquadramento Metodológico

ENQUADRAMENTO METODOLOGICO

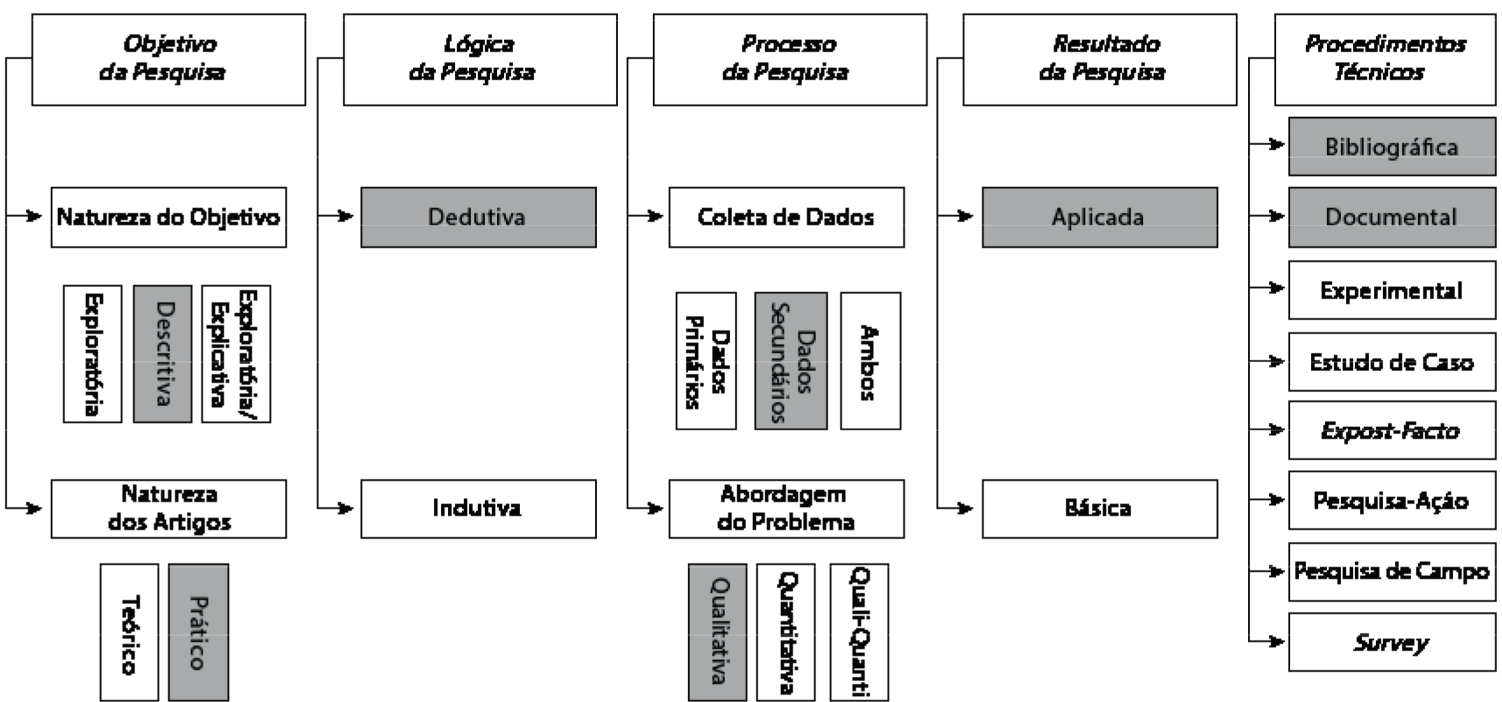

Fonte: Adaptado de Petri (2005) e Richardson (2008)

\subsection{Coleta de Dados}

Para que o objetivo de identificar quais informações exigidas no art. $8^{\circ}$ da Lei de Acesso à Informação estão sendo divulgadas nos sítios eletrônicos dos municípios da região sul do Brasil fosse atingido, utilizaram-se dados de acesso público, disponíveis a qualquer cidadão, de 216 municípios dos Estados do Paraná, Rio Grande do Sul e Santa Catarina.

Esse número foi obtido por meio da utilização de cálculos estatísticos que permitiram a seleção de uma amostra representativa da população. Desta forma, buscou-se evitar a existência de vieses de pesquisa, descrito por Miot (2011) como um problema que pode inviabilizar todo o processo de coleta e, consequentemente, análise dos dados.

Uma vez que foi possível contabilizar o número total de municípios da região estudada - 1191, bem como do total de municípios obrigados a divulgar as informações descritas no artigo $8^{\circ}$ da $\mathrm{LAl}$, utilizou-se a fórmula para seleção de amostra oriunda de uma população finita. Nesses casos, segundo Miot, as fórmulas podem ser ajustadas a partir de um fator de correção, minimizando a dimensão da amostra, conforme Fórmula 1.

$$
\frac{Z^{2} \times P \times Q \times N}{e^{2} \times(N-1)+Z^{2} \times P \times Q}
$$

Onde Z é o Nível de Confiança; P é Quantidade de Acerto esperado (\%); Q é Quantidade de Erro esperado (\%), N é População Total de Municípios com mais de 10 mil habitantes da Região Sul; e é Nível de Precisão.

O nível de confiança adotado (Z) foi de 95\%; a Quantidade de Acerto e Erro esperado (P e Q) foi de 50\%; a População Total (N) representa o total de municípios (493) que se enquadram no parágrafo $4^{\circ}$ do art. 8 da LAl; e o Nível de precisão (e) esperado é de 5\%, conforme parâmetros apresentados por Barbetta (2014).

Desta forma, utilizando-se a fórmula apresentada por Miot (2011) para populações finitas, chegouse a amostra de 216 municípios. Para melhor representatividade, os pesquisadores optaram por selecionar o mesmo número de municípios em cada um dos três Estados da região estudada (72), que foram estratificados em dois grupos: os com maior número de habitantes e os que possuem menor número, conforme dados do Instituto Brasileiro de Geografia e Estatística (IBGE, 2014). 
A seguir, apresentam-se as Tabelas 1 e 2 que contêm, respectivamente, os municípios mais (Estrato A) e menos populosos (Estrato B) que compuseram a população selecionada da pesquisa.

Tabela 1 - Estrato A - Municípios mais Populosos

Estrato A

\begin{tabular}{|c|c|c|c|c|c|c|c|c|}
\hline UF & CIDADE & $N^{\circ}$ HAB & UF & CIDADE & $N^{\circ}$ HAB & UF & CIDADE & $N^{\circ}$ HAB \\
\hline RS & Porto Alegre & 1.472 .482 & PR & Curitiba & 1.864 .416 & SC & Joinville & 554.601 \\
\hline RS & Caxias do Sul & 470.223 & PR & Londrina & 543.003 & SC & Florianópolis & 461.524 \\
\hline RS & Pelotas & 342.053 & PR & Maringá & 391.698 & SC & Blumenau & 334.002 \\
\hline RS & Canoas & 339.979 & PR & Ponta Grossa & 334.535 & SC & São José & 228.561 \\
\hline RS & Santa Maria & 274.838 & PR & Cascavel & 309.259 & SC & Criciúma & 204.667 \\
\hline RS & Gravataí & 270.689 & PR & SJ dos Pinhais & 292.934 & SC & Chapecó & 202.009 \\
\hline RS & Viamão & 251.033 & PR & Foz do Iguaçu & 263.647 & SC & Itajaí & 201.557 \\
\hline RS & Novo Hamburgo & 248.251 & PR & Colombo & 229.872 & SC & $\begin{array}{l}\text { Jaraguá } \\
\text { do Sul }\end{array}$ & 160.143 \\
\hline RS & São Leopoldo & 226.988 & PR & Guarapuava & 176.973 & SC & Lages & 158.846 \\
\hline RS & Rio Grande & 207.036 & PR & Paranaguá & 149.467 & SC & Palhoça & 154.244 \\
\hline RS & Alvorada & 205.683 & PR & Araucária & 131.356 & SC & Bal. Camboriú & 124.557 \\
\hline RS & Passo Fundo & 195.620 & PR & Toledo & 130.295 & SC & Brusque & 119.719 \\
\hline RS & Sapucaia do Sul & 137.750 & PR & Apucarana & 129.265 & SC & Tubarão & 102.087 \\
\hline RS & Uruguaiana & 129.580 & PR & Pinhais & 125.808 & SC & São Bento do Sul & 79.971 \\
\hline RS & Santa Cruz do Sul & 125.353 & PR & Campo Largo & 122.443 & SC & Caçador & 75.048 \\
\hline RS & Cachoeirinha & 125.246 & PR & Arapongas & 113.833 & SC & Camboriú & 72.261 \\
\hline RS & Bagé & 121.500 & PR & Alm Tamandaré & 111.586 & SC & Concórdia & 72.073 \\
\hline RS & Bento Gonçalves & 112.318 & PR & Umuarama & 107.319 & SC & Navegantes & 70.565 \\
\hline RS & Erechim & 101.752 & PR & Cambé & 103.036 & SC & Rio do Sul & 66.251 \\
\hline RS & Guaíba & 98.864 & PR & Piraquara & 102.798 & SC & Araranguá & 65.090 \\
\hline RS & Cachoeira do Sul & 85.830 & PR & Campo Mourão & 92.300 & SC & Gaspar & 63.826 \\
\hline RS & Esteio & 83.846 & PR & $\begin{array}{l}\text { Fazenda } \\
\text { Rio Grande }\end{array}$ & 90.648 & SC & Biguaçu & 63.440 \\
\hline RS & $\begin{array}{l}\text { Santana do } \\
\text { Livramento }\end{array}$ & 83.324 & PR & Sarandi & 89.388 & SC & Indaial & 61.968 \\
\hline RS & ljuí & 82.563 & PR & Paranavaí & 86.218 & SC & Itapema & 55.016 \\
\hline RS & Sapiranga & 79.152 & PR & Francisco Beltrão & 85.486 & SC & Mafra & 55.012 \\
\hline RS & Santo Ângelo & 78.908 & PR & Pato Branco & 78.136 & SC & Canoinhas & 54.079 \\
\hline RS & Alegrete & 78.768 & PR & Cianorte & 76.456 & SC & Içara & 52.284 \\
\hline RS & Lajeado & 77.761 & PR & Telêmaco Borba & 75.054 & SC & Videira & 50.349 \\
\hline RS & Santa Rosa & 71.961 & PR & Castro & 70.454 & SC & Xanxerê & 47.679 \\
\hline RS & Venâncio Aires & 69.521 & PR & Rolândia & 62.590 & SC & São Fco. do Sul & 47.547 \\
\hline RS & Farroupilha & 68.030 & PR & Irati & 59.339 & SC & Laguna & 44.316 \\
\hline RS & Camaquã & 65.628 & PR & União da Vitória & 55.874 & SC & Imbituba & 42.708 \\
\hline RS & Vacaria & 64.564 & PR & Ibiporã & 51.802 & SC & Rio Negrinho & 41.386 \\
\hline RS & Cruz Alta & 63.946 & PR & Prudentópolis & 51.281 & SC & Timbó & 40.515 \\
\hline RS & Campo Bom & 63.767 & PR & $\begin{array}{l}\text { Mal Cândido } \\
\text { Rondon }\end{array}$ & 50.299 & SC & Guaramirim & 39.869 \\
\hline RS & São Borja & 63.089 & PR & Cornélio Procópio & 48.487 & SC & Curitibanos & 39.061 \\
\hline
\end{tabular}


Tabela 2 - Estrato B - Municípios menos Populosos

Estrato B

\begin{tabular}{|c|c|c|c|c|c|c|c|c|}
\hline UF & CIDADE & $\mathrm{N}^{\circ} \mathrm{HAB}$ & UF & CIDADE & $N^{\circ}$ HAB & UF & CIDADE & № HAB \\
\hline RS & Xangri-lá & 13.951 & PR & Balsa Nova & 12200 & SC & Correia Pinto & 14063 \\
\hline RS & Cerro Largo & 13926 & PR & Piên & 12086 & SC & São José do Cedro & 13902 \\
\hline RS & Cacequi & 13.757 & PR & Bocaiúva do Sul & 11996 & SC & Gov. Celso Ramos & 13801 \\
\hline RS & Arroio do Tigre & 13277 & PR & Nova Laranjeiras & 11988 & SC & Siderópolis & 13593 \\
\hline RS & Antônio Prado & 13.274 & PR & Cidade Gaúcha & 11937 & SC & Nova Trento & 13379 \\
\hline RS & Barra do Ribeiro & 13208 & PR & Uraí & 11711 & SC & Ilhota & 13309 \\
\hline RS & Feliz & 13.068 & PR & Nova Aurora & 11659 & SC & Turvo & 12452 \\
\hline RS & Pinheiro Machado & 13011 & PR & Céu Azul & 11589 & SC & São Ludgero & 12192 \\
\hline RS & Bom Princípio & 12.792 & PR & $\begin{array}{l}\text { São Jerônimo da } \\
\text { Serra }\end{array}$ & 11570 & SC & Lebon Régis & 12091 \\
\hline RS & Mostardas & 12679 & PR & Joaquim Távora & 11447 & SC & Campo Alegre & 11982 \\
\hline RS & Salto do Jacuí & 12395 & PR & Centenário do Sul & 11346 & SC & Balneário Rincão & 11824 \\
\hline RS & Nonoai & 12321 & PR & São João do Ivaí & 11342 & SC & Luiz Alves & 11653 \\
\hline RS & Cruzeiro do Sul & 12122 & PR & Itapejara d'Oeste & 11335 & SC & Sangão & 11532 \\
\hline RS & Balneário Pinhal & 12106 & PR & Teixeira Soares & 11321 & SC & Canelinha & 11452 \\
\hline RS & Bom Retiro do Sul & 12058 & PR & Santa Fé & 11297 & SC & Ponte Serrada & 11405 \\
\hline RS & Bom Jesus & 11809 & $P R$ & Inácio Martins & 11294 & SC & Rodeio & 11325 \\
\hline RS & Jaguari & 11631 & PR & Florestópolis & 11265 & SC & Bal. Arroio do Silva & 11248 \\
\hline RS & Vale do Sol & 11608 & PR & Primeiro de Maio & 11222 & SC & Lontras & 11200 \\
\hline RS & Barros Cassal & 11480 & PR & Roncador & 11212 & SC & Gravatal & 11148 \\
\hline RS & Palmares do Sul & 11393 & PR & $\begin{array}{l}\text { Santa Maria do } \\
\text { Oeste }\end{array}$ & 11159 & SC & Imaruí & 11117 \\
\hline RS & $\begin{array}{l}\text { S. Antônio das } \\
\text { Missões }\end{array}$ & 11241 & PR & Paranacity & 10968 & SC & Urubici & 11058 \\
\hline RS & $\begin{array}{l}\text { Capela de } \\
\text { Santana }\end{array}$ & 11198 & PR & Alvorada do Sul & 10965 & SC & Benedito Novo & 11037 \\
\hline RS & Seberi & 11176 & PR & Ribeirão Claro & 10952 & SC & Mondaí & 11034 \\
\hline RS & $\begin{array}{l}\text { Cerro Grande do } \\
\text { Sul }\end{array}$ & 11141 & $P R$ & Ventania & 10934 & SC & Rio dos Cedros & 11019 \\
\hline RS & Redentora & 10938 & PR & Pérola & 10852 & SC & Cunha Porã & 10944 \\
\hline RS & Fontoura Xavier & 10916 & $P R$ & Missal & 10830 & SC & Irineópolis & 10916 \\
\hline RS & Roca Sales & 10909 & PR & São João & 10743 & SC & São Carlos & 10849 \\
\hline RS & Tapera & 10796 & $P R$ & São Pedro do Ivaí & 10733 & SC & Faxinal dos Guedes & 10784 \\
\hline RS & Porto Xavier & 10779 & PR & Iretama & 10730 & SC & Jacinto Machado & 10642 \\
\hline RS & Três Cachoeiras & 10761 & PR & $\begin{array}{l}\text { Nova Prata do } \\
\text { Iguaçu }\end{array}$ & 10710 & SC & Guaraciaba & 10433 \\
\hline RS & Planalto & 10707 & PR & Mariluz & 10534 & SC & Catanduvas & 10244 \\
\hline RS & Ronda Alta & 10633 & PR & $\begin{array}{l}\text { Santa Tereza } \\
\text { do Oeste }\end{array}$ & 10528 & SC & Coronel Freitas & 10236 \\
\hline RS & Arvorezinha & 10585 & PR & Catanduvas & 10463 & SC & Apiúna & 10211 \\
\hline RS & Terra de Areia & 10553 & $P R$ & Alto Piquiri & 10317 & SC & Quilombo & 10201 \\
\hline RS & Sinimbu & 10395 & PR & Barracão & 10187 & SC & Agrolândia & 10115 \\
\hline RS & Constantina & 10086 & PR & Itaipulândia & 10056 & SC & Irani & 10033 \\
\hline
\end{tabular}

Fonte: Adaptado de IBGE (2014) 
A coleta dos dados ocorreu nos sítios eletrônicos dos municípios que compõem a amostra. Os itens analisados foram os seguintes (Quadro 1)

Quadro 1 - Itens analisados quanto ao Art. $8^{\circ}$ da LAI

\begin{tabular}{|l|c|c|c|}
\hline \multicolumn{1}{|c|}{ Itens analisados } & \multicolumn{2}{c|}{ Respostas possíveis } \\
\hline Registro das competências e estrutura organizacional & Sim & Não & Parcial \\
\hline Endereços e telefones de suas unidades e horários de atendimento ao público & Sim & Não & Parcial \\
\hline Registro de quaisquer repasses ou transferências de recursos financeiros & Sim & Não & Parcial \\
\hline Registros de despesas & Sim & Não & Parcial \\
\hline Informações referentes a procedimentos licitatórios & Sim & Não & Parcial \\
\hline Informações sobre os contratos celebrados & Sim & Não & Parcial \\
\hline Dados gerais para o acompanhamento de programas, ações, projetos e obras & Sim & Não & Parcial \\
\hline Respostas às perguntas mais frequentes da sociedade & Sim & Não & Parcial \\
\hline
\end{tabular}

Fonte: Brasil (2011).

Esse procedimento foi realizado no período entre 20 de julho e 02 de agosto de 2015 e os dados de cada município foram registrados em planilhas Excel 2007 para facilitar posteriores totalizações e classificações.

A seguir, apresenta-se a fundamentação teórica, que versa sobre transparência, accountability e acesso à informação pública e controle social.

\section{FUNDAMENTAÇÃO TEÓRICA}

O termo transparência, quando analisada sob a óptica governamental, constitui, de acordo com Allegretti e Platt Neto (2010), um dos elementos da gestão fiscal responsável e é indissociável da governança pública moderna. Para Angélico (2012), o termo corresponde a um conjunto de práticas e iniciativas que promovem e asseguram a visibilidade e acessibilidade das informações e ações governamentais sujeitas ao escrutínio público.

De acordo com Platt Neto et al (2007) a transparência tornou-se, nos últimos anos, um dos pilares da Administração Pública. Porto, Castro e Perottoni (2006), corroboram com esta visão ao afirmar que o tema tem sua importância para avaliação da credibilidade da máquina estatal, bem como para a demonstração da probidade administrativa, gerando confiabilidade no sistema administrativo.

Neste contexto, a transparência nas contas públicas passou a receber maior destaque na legislação brasileira, em prol do controle social e de uma gestão pública responsável (ALLEGRETTI; PLATT NETO, 2007).

A Constituição Federal de 1988 (BRASIL, 1988a) estabeleceu em seu artigo 37 a publicidade na administração pública como um princípio e a definiu em seu $\S 1^{\circ}$ que esta deverá ter caráter educativo, informativo ou de orientação social sem intenção de promover as autoridades ou servidores públicos envolvidos no ato divulgado.

Assim como em outras nações, a corrupção perturba e prejudica os cidadãos brasileiros. Noticiários, de modo contínuo, expõem casos de malversação e desvios de recursos em todas as esferas do poder, levando o país ao 69॰ lugar entre 176 países pesquisados pela organização Transparency Internacional. Ademais, a corrupção é considerada, por Rocha (2011), um atentando contra o mais fundamental dos direitos humanos - à vida por não proporcionar acesso digno à saúde e por não proporcionar condições básicas de moradia, esgotamento sanitário e em termos de conservação de estradas e rodovias.

Na tentativa de banir com a corrupção e incentivar práticas de controle social, o Brasil tem aprimorado as ferramentas de transparência e acesso à informação, permitindo a participação popular na gestão dos recursos públicos - participação essa, defendida por Rocha (2011), por ser o cidadão afetado diretamente pela ação estatal o melhor fiscalizador, tendo em vista que só ele sabe se o ato é efetivamente útil e de qualidade.

Alves (2011) e Corbari (2011) afirmam que uma forma de inibir a corrupção é permitir acesso facilitado do cidadão às informações públicas, aumentando o controle social, bem como o aumento da transparência e da accountability na gestão pública.

Controle social é entendido por Arruda e Teles (2010) como o envolvimento da sociedade nos assuntos de interesse coletivo, ligados à gestão pública, por meio de um conjunto de ações previstas em lei. Este controle tem como objetivo fiscalizar, monitorar e avaliar as condições em que foram executadas as políticas públicas, incluindo-se aí os gastos realizados com dinheiro público. 
De acordo com Rocha (2011) e Angélico (2012), o controle social pode ser exercido também por outros atores que não apenas os cidadãos. Para melhor entendimento, elaborou-se, a partir dos estudos de Soares (2013), o Quadro 02 com a lista dos grupos de usuários e seus interesses.

Quadro 2 - Grupos de usuários e seus interesses

\begin{tabular}{|c|c|}
\hline Usuários & Interesses \\
\hline Cidadãos & $\begin{array}{c}\text { Exercer o controle social, auxiliando na priorização } \\
\text { e fiscalização das ações governamentais. }\end{array}$ \\
\hline $\begin{array}{c}\text { Entidades da Sociedade Civíl } \\
\text { (ONG, Sindicatos, etc.) }\end{array}$ & $\begin{array}{c}\text { A partir de seus objetivos, acompanhar } \\
\text { e fiscalizar a ação governamental }\end{array}$ \\
\hline Partidos políticos & $\begin{array}{c}\text { Acompanhar e fiscalizar a alocação dos recursos } \\
\text { públicos com objetivos políticos-eleitorais. }\end{array}$ \\
\hline $\begin{array}{c}\text { Outras esferas de } \\
\text { Governo ou poderes }\end{array}$ & Fiscalizar o uso de recursos; decidir o auxílio técnico e financeiro; \\
instituir ou alterar das normas vigentes.
\end{tabular}

Fonte: Adaptado de Soares (2013, p. 45-46).

Neste sentido, Pítsica (2011) afirma que exercer o controle social não se trata apenas de um direito, mas de um sinal de amadurecimento da cidadania e do desenvolvimento do país. Para Rocha (2011), os principais entraves para o exercício do controle social são: a estratégia daqueles que querem impedir o controle pela sociedade é propagar que o direito não existe; não é necessário divulgar dados e informações de governo, pois apenas especialistas seriam capazes de entender as contas públicas; a população não têm interesse em fiscalizar, não sendo necessário expor as informações; não existem recursos, pela priorização de gastos ocorrer em confortáveis gabinetes e não em locais em que a população possa participar e; que cabe aos partidos políticos a fiscalização das ações. Ainda de acordo com o autor, estes entraves devem ser discutidos para proporcionar mudanças em âmbito global, permitindo que a população exerça sua garantia constitucional e não espere de seus governantes o bom uso dos recursos públicos (PÍTSICA, 2011). Cabe aos partidos políticos a fiscalização das ações, têm sido discutidas e proporcionaram mudanças em âmbito global, permitindo que a população exerça sua garantia constitucional e não espere de seus governantes o bom uso dos recursos públicos.

A transparência das informações públicas, como mencionado, tem ligação com o princípio da publicidade, previsto no artigo 37 da Carta Magna (BRAIL, 1988a). Antes mesmo deste artigo, a Constituição Federal dispõe, em seu artigo $5^{\circ}$, que é assegurado a qualquer pessoa o acesso às informações detidas pelo Estado. Esta premissa é garantida ao cidadão graças a dispositivos legais desenvolvidos a partir de experiências de outros países.

De acordo com Angélico (2012, p. 51):

Leis de acesso à informação não existem isoladamente no mundo. Em cada país, processos históricos e agendas governamentais ditaram diferentes objetivos para a aprovação e implementação de leis desse tipo. Nesse sentido, torna-se extremamente arriscado e, talvez, inexato ou insuficiente, dizer que uma Lei de Acesso à Informação está "bem implementada" ou é "bem sucedida".

Como mencionado pelo autor, embora a implementação de leis de acesso à informação se deu em cada contexto particular e com base em características históricas e culturais de cada nação, cabe destacar algumas informações relevantes: o Brasil foi apenas o décimo nono país latino-americano a criar seu dispositivo; em pesquisa realizada por Holsen (2011 apud ANGÉLICO, 2012); os cidadãos que demonstram menos interesse em informações públicas são os alemães e os suíços; e a lei de acesso à informação no Reino Unido, sancionada em 2000 apresenta seis objetivos: (i) Aumentar a transparência; (ii) Aumentar a accountability; (iii) Melhorar a qualidade das decisões governamentais; (iv) Melhorar a compreensão da sociedade em relação às decisões governamentais; (v) Aumentar a participação e (vi) Aumentar a confiança.

No contexto brasileiro criou-se, como resultado da tendência mundial supracitada, a Lei $n^{\circ} 9.755$ de 16 de dezembro de 1988 (BRASIL, 1988b), considerada por Allegretti e Platt Neto (2007) como a primeira iniciativa legal no sentido de incorporar a obrigatoriedade da divulgação de informações das contas públicas. Essa lei se materializou com a criação do sítio eletrônico "Contas Públicas", em que todas as entidades gestoras de recursos públicos são obrigadas a disponibilizar determinadas informações orçamentárias e financeiras mensalmente, abrangendo entidades das esferas federal, estadual e municipal, da administração direta e indireta, autárquica e fundacional e de todos os Poderes. 
Anos depois, em 2000, surge a Lei Complementar no. 101, de 04 de maio de 2000, denominada Lei de Responsabilidade Fiscal (LRF) (BRASIL, 2000). Este dispositivo, segundo Bernardo, Rosa e Bianco (2012) é considerado um marco histórico para as Finanças Públicas do país e estabelece um conjunto de normas para as três esferas de governo que concretizou a transparência na Administração Pública. Como importante ferramenta para o equilíbrio das contas públicas, a LRF busca promover a responsabilidade na gestão fiscal, a transparência e o equilíbrio das contas públicas, sendo, na visão de Porto, Castro e Perottoni (2006) importante para dar maior efetividade e maior elasticidade ao termo publicidade. Para os autores, a transparência estabelecida pela LRF é um conceito mais amplo do que a publicidade e exige que a informação seja não apenas publicada, mas que seja relevante, confiável, oportuna e compreensível.

A LRF teve, por meio da Lei Complementar no 131/09, acréscimos importantes quanto à divulgação de seus dados. Por este dispositivo foi estabelecido que a disponibilização, em tempo real, de informações detalhadas sobre a execução orçamentária e financeira da União, dos Estados, do Distrito Federal e dos Municípios, criando os conhecidos portais da transparência.

Seguindo essa tendência, em 18 de novembro de 2011 promulgou-se a Lei 12.527, denominada Lei de acesso à informação - LAl, que busca produzir efeitos concretos dispostos pelos artigos 50, $37^{\circ}$ e $216^{\circ}$ da Constituição Federal de 1988. A LAl, em seu artigo 30, apresenta cinco importantes diretrizes, para atingimento de seu objetivo, a saber; a) observância da publicidade como preceito geral e do sigilo como exceção; b) divulgação de informações de interesse público, independentemente de solicitações; c) utilização de meios de comunicação viabilizados pela tecnologia da informação; d) fomento ao desenvolvimento da cultura de transparência na administração pública e e) desenvolvimento do controle social da administração pública (BRASIL, 2011).

Em seu artigo $8^{\circ}$, a Lei de Acesso à Informação apresenta as formas de divulgação das informações pelos entes estatais. Cabe ressaltar que a obrigatoriedade de divulgação das informações abaixo é exclusiva da União, dos Estados e dos Municípios com mais de 10 mil habitantes.

\begin{abstract}
Art. $8^{\circ}$ É dever dos órgãos e entidades públicas promover, independentemente de requerimentos, a divulgação em local de fácil acesso, no âmbito de suas competências, de informações de interesse coletivo ou geral por eles produzidas ou custodiadas. $\S 1 \circ \mathrm{Na}$ divulgação das informações a que se refere o caput, deverão constar, no mínimo: I - registro das competências e estrutura organizacional, endereços e telefones das respectivas unidades e horários de atendimento ao público; II - registros de quaisquer repasses ou transferências de recursos financeiros; III - registros das despesas; IV - informações concernentes a procedimentos licitatórios, inclusive os respectivos editais e resultados, bem como a todos os contratos celebrados; $\mathrm{V}$ - dados gerais para o acompanhamento de programas, ações, projetos e obras de órgãos e entidades; e VI - respostas a perguntas mais frequentes da sociedade. $\S 2^{\circ}$ Para cumprimento do disposto no caput, os órgãos e entidades públicas deverão utilizar todos os meios e instrumentos legítimos de que dispuserem, sendo obrigatória a divulgação em sítios oficiais da rede mundial de computadores (BRASIL, 2011).
\end{abstract}

Com essas informações, espera-se, que os cidadãos possam exercer o controle social de maneira efetiva no setor público, contribuindo para a inibição da corrupção e das malversações citadas por Rocha (2011) que atentam contra a vida dos mesmos.

Em caso de descumprimento da LAl, o artigo 33 apresenta as sanções àqueles que não respeitarem seus dispositivos. Das mais leves, como a suspensão, às mais graves, como a possibilidade de responder por improbidade administrativa. As pessoas físicas ou entidades de cunho privado que não cumprem o disposto na LAl estão sujeitas à advertência, multa, rescisão do vínculo com o poder público, suspensão temporária da participação em licitação e contratos públicos.

A seguir, apresentam-se as condutas passíveis de sansões: (i) recusar-se a fornecer informação pública, fazê-lo intencionalmente de forma incorreta, incompleta ou imprecisa, ou agir de má-fé na análise de solicitações de informação. (ii) utilizar indevidamente, subtrair, destruir, inutilizar, desfigurar, alterar ou ocultar a informação; (iii) acessar ou permitir o acesso indevido à informação sigilosa ou pessoal; (iv) Impor sigilo à informação para proveito pessoal ou de terceiro; (v) Ocultar informação da autoridade superior.

Considera-se informação sigilosa, conforme art. 4 da LAl, aquela submetida temporariamente à restrição de acesso por sua imprescindibilidade para a segurança da sociedade e do Estado. De forma mais específica, são sigilosas as informações que possam colocar em risco a defesa e a soberania nacional, bem como prejudicar as relações comerciais e diplomáticas do país, as que foram fornecidas por estados e organismos internacionais também em caráter sigiloso e que possam pôr em risco a vida, a segurança ou a saúde do povo e a estabilidade econômica do país, entre outros. 
Cabe ressaltar que, conforme o Art. 21 da LAl, os documentos e as informações sobre condutas que impliquem a violação de direitos humanos praticada por ou a mando de agentes públicos, não podem ser objeto de restrição de acesso. No artigo seguinte, apresentam-se que sigilo de justiça, segredos industriais e as informações pessoais relacionadas à intimidade, à vida privada, à honra e imagem estão assegurados pela LAI.

Na próxima seção serão apresentados os resultados do levantamento dos itens, bem como a análise dos mesmos.

\section{RESULTADOS}

Após pesquisa nos sítios eletrônicos dos 216 municípios que compuseram a amostra, apresentam-se gráficos e tabelas para melhor compreensão dos resultados encontrados e atendimento do objetivo desta pesquisa.

Os municípios foram estratificados em dois grupos - os mais populosos (Estrato $A$,) e os menos populosos (Estrato B), divididos igualmente em 108 cidades, sendo 36 de cada Unidade da Federação (UF) que compõem a região sul do país.

A seguir, nos Gráficos 1 a 4, inicia-se a apresentação dos dados dos itens registro das competências e estrutura organizacional e divulgação do endereço, telefone e horário de atendimento ao público.

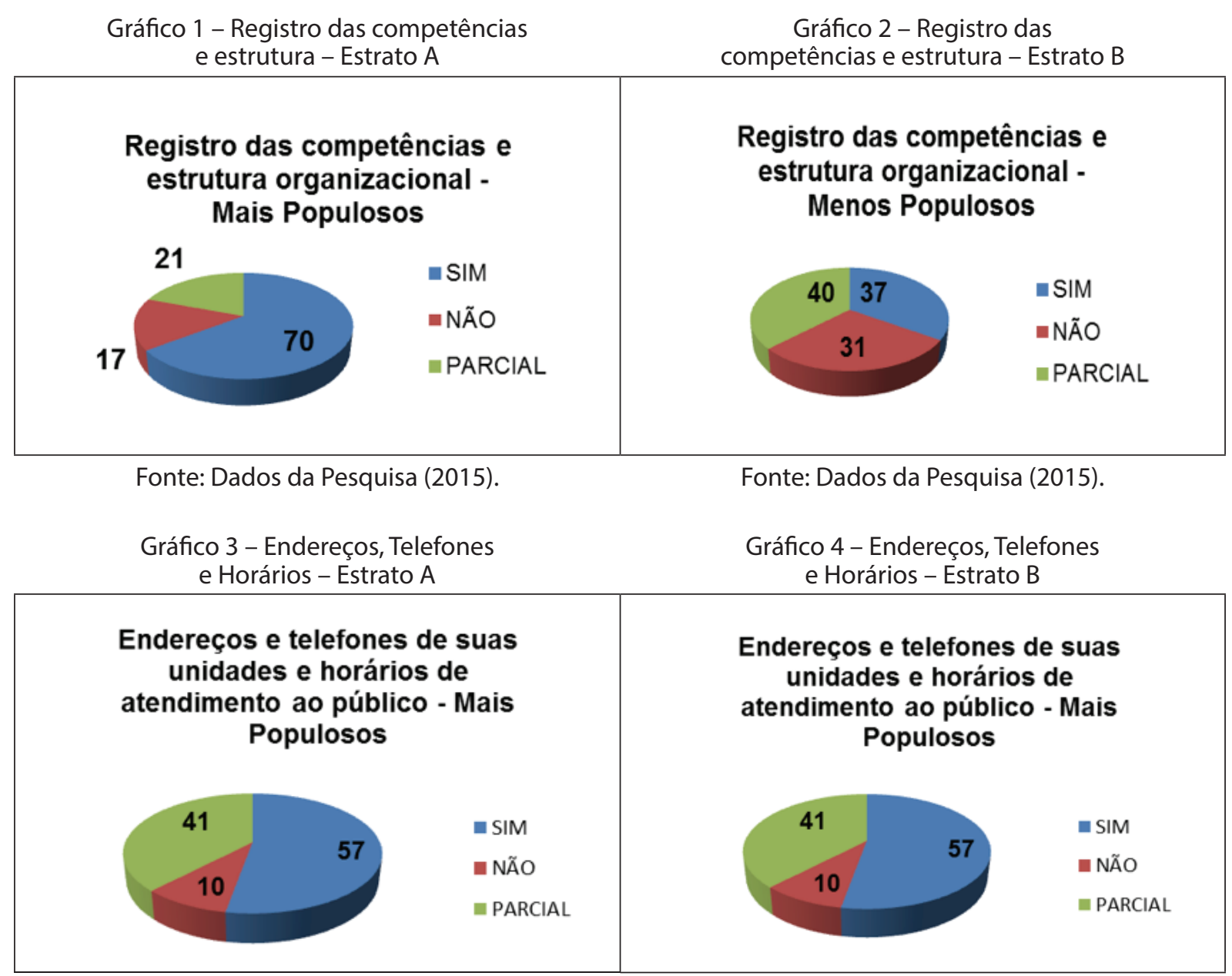

Fonte: Dados da Pesquisa (2015).

Fonte: Dados da Pesquisa (2015).

Dos 108 municípios mais populosos, 17 (15\%) não possuem nenhuma informação das competências e estrutura organizacional. Quando analisado o estrato dos municípios com menor população, o percentual quase dobra (29). Outro aspecto percebido é que 19\% dos municípios do Estrato A e $37 \%$ do B apresentam de forma "parcial" as informações deste tópico, pois ou divulgam a estrutura organizacional, ou o registro das competências. Este cenário corrobora com os ensinamentos de Rocha (2011), que considera a despreocupação dos agentes públicos em fornecer informações aos cidadãos uma barreira ao controle social.

Em relação à divulgação dos endereços e telefones de suas unidades e horários de atendimento ao público, é possível identificar que apenas $53 \%$ dos municípios mais populosos disponibilizam o endereço, os telefones 
e o horário de atendimento de seus entes. Quando analisados os municípios do Estrato B, esse percentual cai para $36 \%$, demonstrando que, independentemente do número de habitantes, muitos municípios não cumprem este requisito, dificultando o acesso do cidadão aos serviços públicos.

Sobre o registro de quaisquer repasses ou transferências de recursos financeiros, oitenta e três municípios (ou 77\%) do Estrato A e 66\% dos municípios menos populosos divulgam os repasses ou transferências de recursos financeiros. Quanto ao registro de despesas, os percentuais verificados nos dois estratos são maiores: $91 \%$ e $80 \%$. Estes percentuais, assim como no caso dos repasses e transferências, demonstram que, de modo geral, os municípios divulgam em seus portais eletrônicos as informações das transferências financeiras.

Gráfico 5 - Registro das competências e estrutura - Estrato A

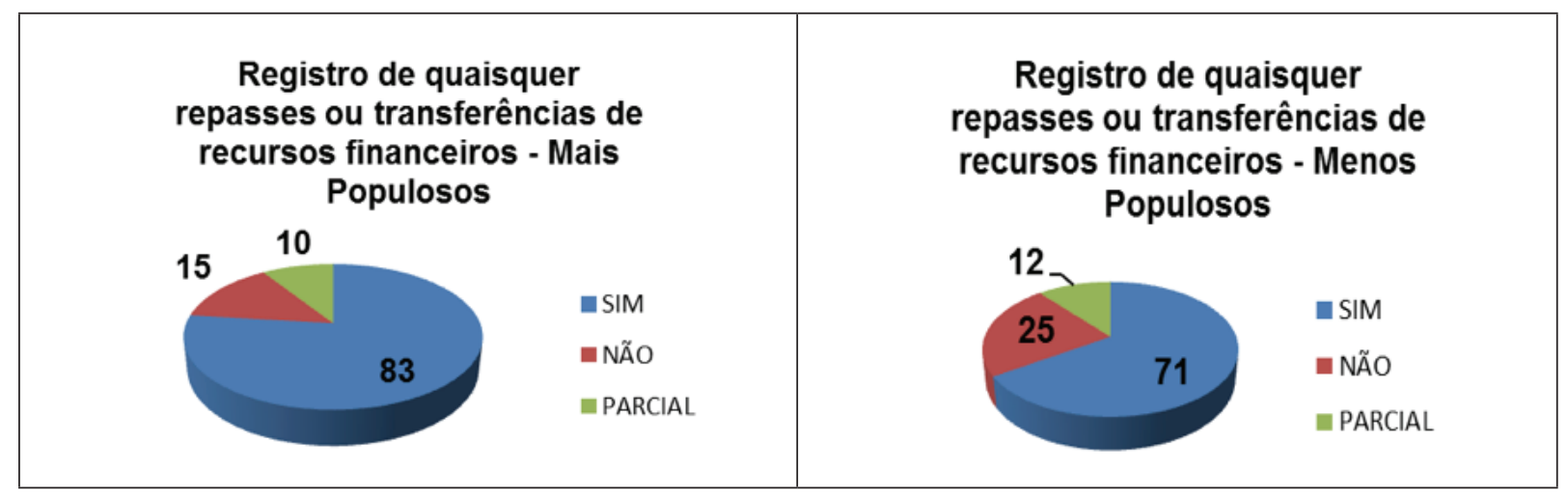

Fonte: Dados da Pesquisa (2015).
Gráfico 6 - Registro das competências e estrutura - Estrato B

Gráfico 7 - Registro de quaisquer repasses e transferências financeiras - Estrato A

Gráfico 8 - Registro de quaisquer repasses e transferências financeiras - Estrato B

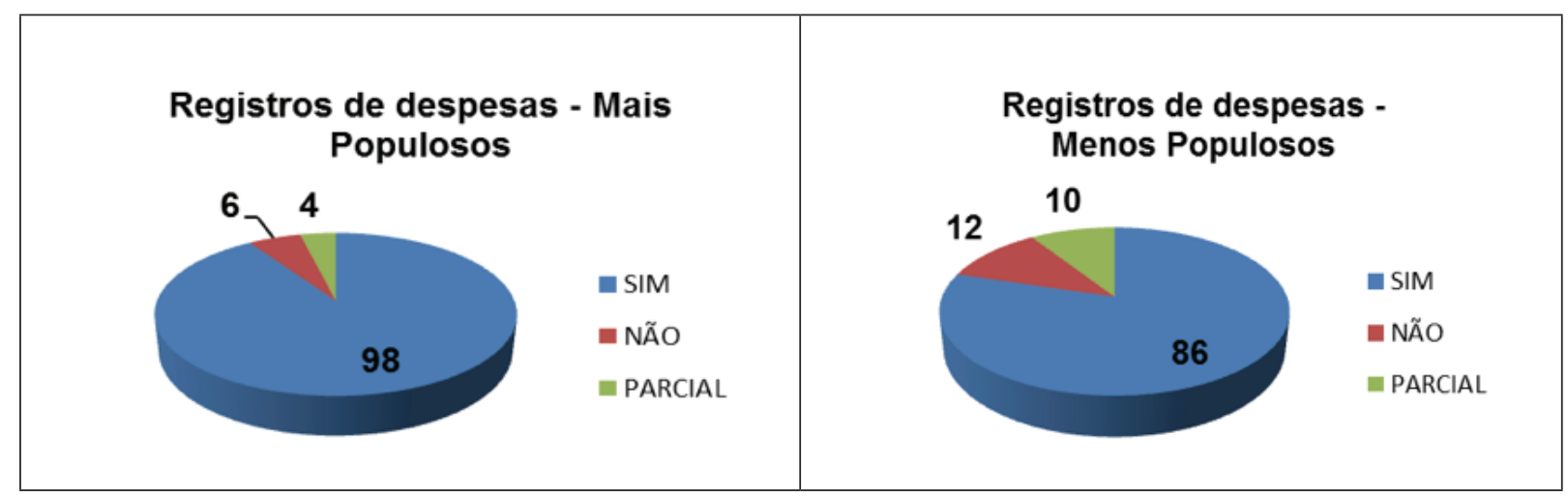

Fonte: Dados da Pesquisa (2015).

Fonte: Dados da Pesquisa (2015).

A seguir, apresentam-se os resultados e as análises dos quatro últimos itens: informações referentes a procedimentos licitatórios, informações sobre os contratos celebrados, dados gerais para o acompanhamento de programas, ações, projetos e obras e respostas às perguntas mais frequentes da sociedade. 
Gráfico 9 - Informações sobre procedimentos licitatórios - Estrato A

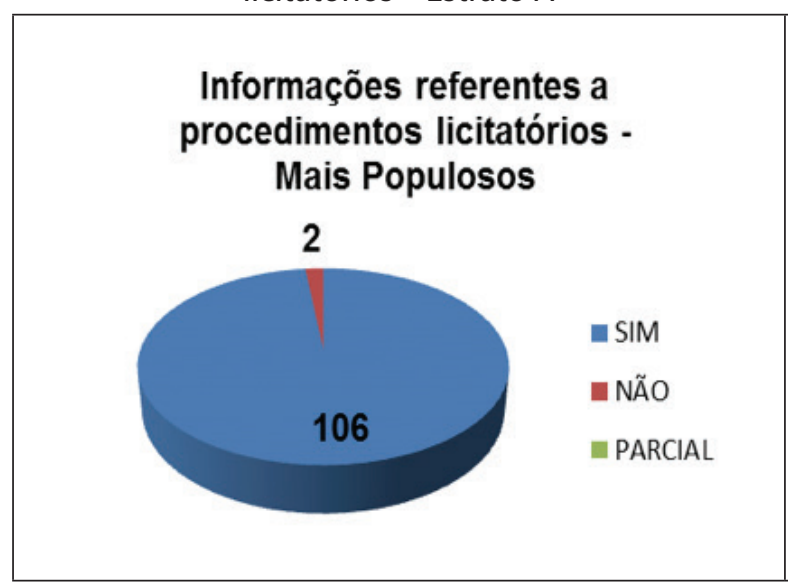

Fonte: Dados da Pesquisa (2015).
Gráfico 10 - Informações sobre procedimentos licitatórios - Estrato B

\section{Informações referentes a procedimentos licitatórios - Menos Populosos}

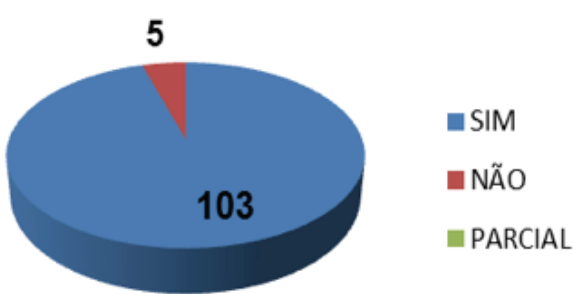

Fonte: Dados da Pesquisa (2015).

Quadro 3 - Informações sobre os contratos celebrados

\begin{tabular}{|c|c|c|c|c|c|c|}
\hline \multicolumn{7}{|c|}{ Informações sobre os contratos celebrados } \\
\hline & \multicolumn{3}{|c|}{$\begin{array}{c}\text { Municípios Mais Populosos } \\
\text { Estrato } A\end{array}$} & \multicolumn{3}{c|}{ Municípios Menos Populosos } \\
Estrato $B$ \\
\hline Op. de Resposta & SIM & NÃO & PARCIAL & SIM & NÃO & PARCIAL \\
\hline Frequência & 98 & 10 & 0 & 92 & 13 & 3 \\
\hline Freq. Relativa & $91 \%$ & $9 \%$ & 0 & $85 \%$ & $12 \%$ & $3 \%$ \\
\hline
\end{tabular}

Fonte: Dados da Pesquisa (2015)

Em relação à publicação de dados sobre os processos licitatórios e os contratos celebrados, as prefeituras de ambos estratos atingiram os melhores percentuais. Dos municípios mais populosos, quanto aos processos licitatórios, 98\% dispõe de informações em seus sítios eletrônicos. Na outra extrema, cento e três municípios (95\%) adotam o mesmo procedimento.

Acerca dos contratos celebrados, os percentuais de divulgação continuam superiores a $80 \%$, sendo, mais especificamente, de $91 \%$ para os que compõem o Estrato A e de $85 \%$ o Estrato B.

Importante salientar que, conforme Soares (2013) uma das formas mais utilizadas por agentes públicos para desvio de verbas e corrupção é por meio de licitações e contratos fraudulentos e em desacordo com a Lei das Licitações, a Lei 8.666/1993.

Quadro 4 - Dados para o acompanhamento de programas, ações, projetos e obras

\begin{tabular}{|c|c|c|c|c|c|c|}
\hline \multirow[b]{2}{*}{ Op. de Resposta } & \multicolumn{3}{|c|}{$\begin{array}{c}\text { Municípios Mais Populosos } \\
\text { Estrato A }\end{array}$} & \multicolumn{3}{|c|}{$\begin{array}{c}\text { Municípios Menos Populosos } \\
\text { Estrato } B\end{array}$} \\
\hline & SIM & NÃO & PARCIAL & SIM & NÃO & PARCIAL \\
\hline Frequência & 68 & 14 & 26 & 47 & 17 & 44 \\
\hline Freq. Relativa & $63 \%$ & $13 \%$ & $24 \%$ & $43 \%$ & $16 \%$ & $41 \%$ \\
\hline
\end{tabular}

Fonte: Dados da Pesquisa (2015) 
O acompanhamento de programas, ações, projetos e obras permitem ao cidadão, público-alvo da ação governamental e considerado por Rocha (2011) como o melhor agente de controle social, a fiscalização dos atos da Administração. No entanto, o direito da população às informações relativas a esses itens não é irrestrito. Pelo contrário, nos municípios com mais habitantes, identificou-se que $63 \%$ deles disponibilizam dados gerais de acompanhamento dos programas, ações, projetos e obras. Já os municípios menores em termos populacionais, esse percentual é ainda menor (43\%). Importante salientar que, nos dois estratos, identificouse significativos percentuais ( $24 \%$ e $41 \%$ ) de municípios que fornecem informações parciais, ou seja, que divulgam pelo menos uma forma de acompanhamento, seja de obras, programas, etc.

Quadro 5- Respostas às perguntas mais frequentes da sociedade

\begin{tabular}{|c|c|c|c|c|c|c|}
\hline & \multicolumn{3}{|c|}{$\begin{array}{c}\text { Municípios Mais Populosos } \\
\text { Estrato } A\end{array}$} & \multicolumn{3}{c|}{$\begin{array}{c}\text { Municípios Menos Populosos } \\
\text { Estrato } B\end{array}$} \\
\hline Op. de Resposta & SIM & NÃO & PARCIAL & SIM & NÃO & PARCIAL \\
\hline Frequência & 67 & 36 & 5 & 42 & 63 & 3 \\
\hline Freq. Relativa & $62 \%$ & $33 \%$ & $5 \%$ & $39 \%$ & $58 \%$ & $3 \%$ \\
\hline
\end{tabular}

Fonte: Dados da Pesquisa (2015)

Em relação ao Quadro 5 - quesito respostas às perguntas mais frequentes da sociedade, sessenta e dois por cento dos municípios mais populosos disponibilizam para consulta as perguntas mais frequentes, enquanto $39 \%$ dos municípios menos populosos adotam a mesma prática. Neste último estrato percebeu-se que mais da metade (63) não dispõe de link de acesso para consulta das informações supracitadas. Esta situação não é muito distante dos municípios mais populosos, uma vez que em um terço destes não foram localizadas as perguntas mais frequentes da sociedade.

\section{CONCLUSÃO}

A legislação sobre transparência na legislação brasileira é tema relativamente recente na literatura. Embora seja considerado um princípio da gestão fiscal responsável, inserido a partir da Lei de Responsabilidade Fiscal e ligado ao princípio constitucional da publicidade (PLATT NETO et al, 2010), o tema tem sido discutido pela comunidade acadêmica em conjunto com outros conceitos, como governança, evidenciação e accountability.

Com objetivo de banir a corrupção e incentivar práticas de controle social, o Brasil vem aprimorando as ferramentas de transparência e acesso à informação, permitindo a participação popular na gestão dos recursos públicos - participação essa, defendida por Rocha (2011), como fundamental para o exercício do controle social, uma vez que é o cidadão, afetado diretamente pela ação estatal, o ator mais indicado para fiscalizar e controlar a qualidade do serviço público prestado.

Como apresentado, Alves (2011) e Corbari (2011) corroboram com Rocha (2011) ao afirmarem que a corrupção pode ser inibida pelo acesso facilitado do cidadão às informações públicas, proporcionando o aumento do controle social, da transparência e da accountability na gestão pública.

Neste trabalho, o conceito de controle social adotado foi o de Arruda (2010), que considera que envolvimento da sociedade nos assuntos de interesse público tem o objetivo de fiscalizar, monitorar e avaliar as condições em que foram executadas as políticas públicas, incluindo-se aí os gastos realizados com dinheiro público.

A análise de dados seu deu por meio de consultas aos sítios eletrônicos de 216 municípios da região sul do país, realizadas entre 20 de julho e 02 de agosto de 2015, com base nos dados disponíveis neste período, fato que pode ser considerado a limitação da pesquisa.

A partir do resultado dessas consultas, apresentada na seção 4, entende-se que o objetivo desta pesquisa, que é identificar o percentual de municípios da região sul do Brasil que divulgam as informações exigidas no art. $8^{\circ}$ da Lei de Acesso à Informação em sítios eletrônicos foi atendido.

Além das reflexões já apresentadas na seção anterior, cabe destacar que a maioria dos municípios apresenta os dados por intermédio de bases de dados de empresas de tecnologia. A partir desta constatação, deduz-se que muitos municípios não possuem recursos humanos, financeiros e estrutura suficientes para o cumprimento das exigências da LAI. Contudo, entende-se que esta situação não deve impedir o exercício do controle social por parte do cidadão.

Outro aspecto relevante constatado foi o alto percentual obtido pelos municípios por ambos os estratos quanto às informações sobre os procedimentos licitatórios e informações sobre os contratos celebrados - mais 
de $85 \%$ disponibilizam as informações sobre as formas de contratação, questões importantes para mitigar o uso incorreto ou até mesmo o desvio dos recursos públicos, conforme apresentado por Soares (2013).

No entanto, no outro extremo estão os dados gerais para o acompanhamento de programas, ações, projetos e obras. Percebe-se que estas informações não são publicadas ou o são, mas de forma parcial, por pouco menos da metade dos municípios pesquisados (101), fato que demonstra a pouca preocupação dos agentes públicos e políticos em divulgar dados de forma tempestiva para facilitar o controle social.

$\mathrm{O}$ menor percentual foi evidenciado no quesito respostas às perguntas mais frequentes da sociedade. Apenas $50,4 \%$ dos municípios divulgam as respostas mais frequentes, dados que poderiam facilitar a interação entre Administração e administrados.

De modo geral, conclui-se que os dados permitem aos pesquisadores afirmarem que os municípios da região sul do Brasil, com população superior à 10 mil habitantes, atendem parcialmente aos requisitos apresentados no Art. 8 da Lei de Acesso à Informação - percepção que responde o problema de pesquisa e o objetivo propostos.

Com essas informações, espera-se, que os cidadãos possam cobrar do poder público a melhoria na qualidade das informações de interesse público divulgadas, exercendo o controle social e contribuindo para a inibição da corrupção e das malversações citadas por Rocha (2011) que atentam contra a vida dos mesmos.

Recomenda-se, a futuros pesquisadores, a verificação do Índice de Transparência de Estados e Municípios desenvolvido pela Controladoria Geral da União (CGU) na amostra selecionada para avaliar o grau de cumprimento às normas de Lei de Acesso e refletir sobre o cenário de transparência não apenas na região sul, mas em todas as regiões do Brasil.

\title{
THE LAW OF ACCESS TO INFORMATION AS AN INSTRUMENT OF SOCIAL CONTROL : DIAGNOSIS OF THE SOUTHERN STATES IN BRAZIL REGARDING ARTICLE 8 OF THE LAW 12527/2011
}

\begin{abstract}
This study aims to identify the percentage of municipalities in southern Brazil that disclose the information required by art. 8 of the Access to Information Act in their websites. Regarding the purpose, this research can be classified as descriptive of deductive logic, qualitative approach , supported by literature and documents, and carried out through consultations to electronic sites of 216 municipalities. From the collected data, it is concluded that, in general, municipalities in southern Brazil, with a population of more than 10 thousand inhabitants, partly meet the requirements set out in art . 8 of LAI. From these results, it is expected that citizens can demand from the government an increase in the quality of the information disclosed to the public interest, thus exerting social control and contributing to the improvement of public administration and inhibition of corruption.
\end{abstract}

Keywords: Law on Access to Information. Transparency. Social control. 


\section{REFERÊNCIAS}

ALLEGRETTI, D. S.; PLATT NETO, O. A. Funcionalidades, limitações e potencialidades do Portal da Transparência do Estado do Rio Grande do Sul. Revista Catarinense da Ciência Contábil, Florianópolis, v. 9, n. 26, p. 79-95, abr./jun. 2010.

ALVES, D. P. Acesso à informação pública no Brasil: um estudo sobre a convergência e a harmonia existentes entre os principais instrumentos de transparência e de controle social. In: Concurso de Monografias da CGU, 6. , 2011. Trabalhos premiados. Brasília: ESAF, 2011. p. 231-294. Disponível em: <http://www.esaf.fazenda.gov.br/ premios/premios-1/premios-realizados/pasta-concurso-de-monografias-da-cgu/concurso-de-monografias-dacgu-2011/profissionais/mencao-honrosa>. Acesso em: 1 nov. 2015.

ANGÉLICO, F. Lei de Acesso à Informação e seus possíveis desdobramentos à Accountability Democrática no Brasil. 2012. 133 f. Dissertação (Mestrado em Administração Pública e Governo) - Fundação Getúlio Vargas, São Paulo, 2012.

ARRUDA, F.A; TELES, J. S. A importância do Controle Social na Fiscalização dos Gastos Públicos. Revista Razão Contábil e Finanças, Fortaleza, v. 1, n. 1, 2010. Disponível em: <http://institutoateneu.com.br/ojs/index.php/ RRCF/article/view/3/5>. Acesso em: 1 nov. 2015.

BARBETTA, P. A. Estatística Aplicada às Ciências Sociais. 9. ed. Florianópolis: Editora UFSC, 2014.

BERNARDO, Fabiano D.; ROSA, M. M.; BIANCO P. A Lei de Responsabilidade Fiscal e o Controle dos Gastos Públicos da União. In: Congresso Internacional de Administração, 2012, Ponta Grossa, PR. Anais do ADMPG. Ponta Grossa: UEPG, 2012.

BRASIL, Constituição da República Federativa do Brasil de 1998. [1988a]. Disponível em: <http://www. planalto.gov.br/ccivil_03/constituicao/constituicao.htm>. Acesso em: 26 mar. 2015.

BRASIL, Lei 9.755, de 16 de dezembro de 1998. [1988b]. Disponível em: <http://www.planalto.gov.br/ CCivil_03/leis/L9755.htm>. Acesso em: 26 mar. 2015.

BRASIL, Lei Complementar n 101, de 4 de maio de 2000 - Lei de Responsabilidade Fiscal. [2000]. Disponível em: <http://www.planalto.gov.br/ccivil_03/leis/LCP/Lcp101.htm>. Acesso em: 21 mar. 2015.

BRASIL, Lei 12.527, de 18 de novembro de 2011 - Lei de Acesso à Informação. [2011]. Disponível em: <http://www.planalto.gov.br/ccivil_03/_ato2011-2014/2011/lei/l12527.htm>. Acesso em 26 mar. 2015.

CORBARI, E. C. Accountability: prática de governança pública e mecanismo de controle social. Revista TCMRJ, Rio de Janeiro, n. 46, p. 12-17, 2011.

GIL, A. C. Métodos e técnicas de pesquisa social. 5. ed. São Paulo: Atlas, 1999.

INSTITUTO BRASILEIRO DE GEOGRAFIA E ESTATÍSTICA (IBGE). Estimativas populacionais para os municípios brasileiros em 01.07.2014. [2014]. Disponível em: <http://www.ibge.gov.br/home/estatistica/populacao/ estimativa2014/estimativa_dou.shtm>. Acesso em: 26 mar. 2015.

INSTITUTO BRASILEIRO DE PLANEJAMENTO TRIBUTÁRIO (IBPT). Estudos do IBPT: Pelo 5º ano seguido, Brasil arrecada muito, mas não dá retorno. Disponível em: <http://www.ibpt.com.br/estudos/estudos.Ist.php >. Acesso em: 1 jun. 2015.

JARDIM, J. M. A lei de acesso à informação pública: dimensões político-informacionais. In: Encontro Nacional de Pesquisa em Ciência da Informação (ENANCIB), 13., 2012, Rio de Janeiro, RJ. Anais do ENANCIB 2012. Rio de Janeiro: ANCIB, 2012.

MIOT, H. A. Tamanho da amostra em estudos clínicos e experimentais. Jornal Vascular Brasileiro, v. 10, n. 4, editorial, 2011. 
PETRI, Sérgio Murilo. Modelo para apoiar a avaliação das abordagens de gestão de desempenho e sugerir aperfeiçoamentos: sob a ótica construtivista. 2005. 265 f. Tese (Doutorado em Engenharia da Produção) Universidade Federal de Santa Catarina, Florianópolis, 2005.

PÍTSICA, G. B. P. Breves reflexões sobre Controle Externo e Controle Social. Revista Controle, Fortaleza, v. 9, n. 2. p. 253-277, 2011.

PLATT NETO, Orion Augusto et al. Publicidade e transparência das contas públicas: obrigatoriedade e abrangência desses princípios na administração pública brasileira. Contabilidade Vista \& Revista, Belo Horizonte, v. 18, p. 75-94, 2007.

PORTO, Éderson G.; CASTRO, Fábio C. L. de; PEROTTONI, Felipe L. A Lei de Responsabilidade Fiscal e os meios eletrônicos como forma de promoção da transparência fiscal na gestão pública. Jus Navigandi, Teresina, n. 1080, jun. 2006. Disponível em: <http://jus2.uol.com.br/doutrina/texto.asp?id=8533>. Acesso em: 23 jul. 2015.

RAUPP, F. M.; BEUREN, Ilse M. Metodologia da pesquisa aplicável às ciências sociais. In: BEUREN, I. M. (Org.). Como elaborar trabalhos monográficos em contabilidade: teoria e prática. São Paulo: Atlas, 2003. p. 77-97.

RICHARDSON, R. J. Pesquisa Social, Métodos e Técnicas. 3. ed. São Paulo: Atlas, 2008.

ROCHA, Z. J. Os Tribunais de Contas e os desafios para promoção do controle social. Revista TCMRJ, Rio de Janeiro, n. 46, p. 4-11, 2011.

SCHEDLER, Andreas. Conceptualizing Accountability. In: SCHEDLER, Andreas; DIAMOND, Larry; PLATTNER, Mark F. (Eds.). The Self-Restraining State: Power and Accountability in New Democracies. Colorado: Lynne Rienne. 1999. p. 13-28.

SOARES, L. L. Transparência em compras públicas: Proposta de um Índice da Transparência na Gestão de Compras Públicas Aplicado aos Websites de Municípios Brasileiros com mais de 100 mil habitantes. 2013.168 f. Dissertação (Mestrado em Contabilidade) - Universidade Federal de Santa Catarina, Florianópolis, 2013. 